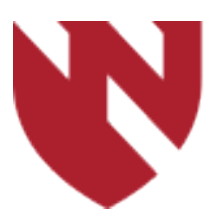

September 2020

\title{
Patterns of Opiate Use and Prescription Practices in Isolated Orthopedic Trauma Part One: Defining the Problem and Creating Guidelines
}

\author{
David J. Kusin \\ University of Nebraska Medical Center \\ Emily A. Boes \\ University of Nebraska Medical Center \\ Zachary C. Bailey \\ University of Nebraska Medical Center \\ Erin L. Stockwell \\ University of Nebraska Medical Center \\ Ryan E. Miller \\ University of Nebraska Medical Center
}

Tell us how you used this information in this short survey.

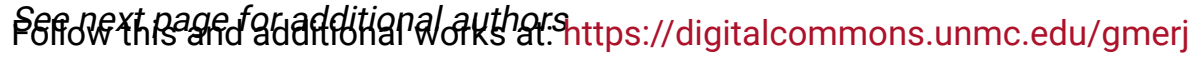

Part of the Higher Education Commons, and the Medicine and Health Sciences Commons

\section{Recommended Citation}

Kusin, D. J., Boes, E. A., Bailey, Z. C., Stockwell, E. L., Miller, R. E., Samson, K. K., Putnam, S. M., Siebler, J. C., , Mormino, M. Patterns of Opiate Use and Prescription Practices in Isolated Orthopedic Trauma Part One: Defining the Problem and Creating Guidelines. Graduate Medical Education Research Journal. 2020 Sep 29; 2(1). https://digitalcommons.unmc.edu/gmerj/vol2/iss1/64

This Conference Proceeding is brought to you for free and open access by DigitalCommons@UNMC. It has been accepted for inclusion in Graduate Medical Education Research Journal by an authorized editor of DigitalCommons@UNMC.For more information, please contact digitalcommons@unmc.edu. 
Patterns of Opiate Use and Prescription Practices in Isolated Orthopedic Trauma Part One: Defining the Problem and Creating Guidelines

\section{Creative Commons License}

\section{(c) (i) $\Theta($}

This work is licensed under a Creative Commons Attribution-Noncommercial-No Derivative Works 4.0 License.

\section{Authors}

David J. Kusin, Emily A. Boes, Zachary C. Bailey, Erin L. Stockwell, Ryan E. Miller, Kaeli K. Samson, Sara M. Putnam, Justin C. Siebler, and Matthew Mormino 
state. Several medications, including hormonal therapies, constipation inducing drugs, laxatives, and illicit drugs have been associated with ischemic colitis. Taking a thorough medication history is essential when a patient is diagnosed with ischemic colitis. The recognition of medication induced colonic ischemia and prompt

discontinuation of offending agent is vital to patient outcomes.

https://doi.org/10.32873/unmc.dc.gmerj.2.1.060

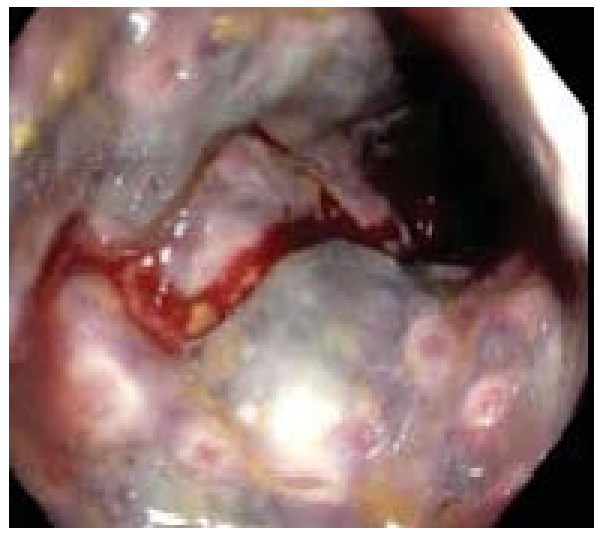

Figure 1. Colonoscopy demonstrating a diffusely edematous, ulcerated, and violaceous segment of the sigmoid colon

\section{Rural Otolaryngology - A Review of Resident Education and the Impact on Future Practice Selection Lauren Klute', Christie Barnes', Matthew Johnson 1,2, Kari Nelson ${ }^{3}$ \\ ${ }^{1}$ University of Nebraska Medical Center, Department of Otolaryngology \\ ${ }^{2}$ Ear, Nose and Throat Physicians of Kearney, Kearney, NE \\ ${ }^{3}$ University of Nebraska Medical Center, Department of Graduate Medical Education}

\section{Mentor: Christie Barnes}

Program: Otolaryngology

Type: Original Research

Background: The University of Nebraska Medical Center, Department of Otolaryngology - Head and Neck Surgery (OHNS) established a rural residency rotation in Kearney, Nebraska, in 2016. Each resident spends two months on the service as a junior (years two or three), and two months as a senior (years four or five). It has been cited that residency rotations in rural practices are a significant factor in retention of family practice and surgical physicians, however, there is not similar data available for Otolaryngology. This study provides data from current and prior OHNS residents on their rural rotation experience and the factors that contributed to future practice decisions.

Methods: In this qualitative study, we used a semi-structured interview guide to probe rural rotation participants on their experience and the influence the rotation had on their future practice decisions.

Results: The rural rotation was influential in residents' selection of future practice and did encourage residents to pursue rural practice. The benefits of the rotation included increased autonomy, diversity of cases, education in the private practice environment, and improved quality of life. The disadvantages included time away from family.

Conclusion: The University of Nebraska Medical Center OHNS Rural Rotation provides invaluable experience, education, and training. The rotation was influential in the selection of future practices and encouraged several residents to pursue rural Otolaryngology practices. A rural rotation experience in residency may lead to retention of Otolaryngologists for rural areas.

https://doi.org/10.32873/unmc.dc.gmerj.2.1.062

\section{Problem and Creating Guidelines Matthew A. Mormino' \\ ${ }^{1}$ University of Nebraska Medical Center, Department of Orthopaedic Surgery and Rehabilitation \\ 2University of Nebraska Medical Center, College of Medicine \\ ${ }^{3}$ Loma Linda University Medical Center \\ ${ }^{4}$ University of Nebraska Medical Center, College of Public Health, Department of Biostatistics}

Patterns of Opiate Use and Prescription Practices in Isolated Orthopedic Trauma Part One: Defining the

David J. Kusin'1, Emily A. Boes², Zachary C. Bailey ${ }^{1}$, Erin L. Stockwell', Ryan E. Miller ${ }^{3}$, Kaeli K. Samson ${ }^{4}$, Sara M. Putnam¹, Justin C. Siebler ${ }^{1}$,

Mentor: Matthew A Mormino

Program: Orthopaedic Surgery and Rehabilitation

Type: Original Research

Background: About $80 \%$ of the global supply of opiates is consumed in the United States, yet opioid use is associated with significant morbidity and safer approaches to pain control exist1-15. The purpose of this two- part study is to quantify our opioid prescribing practices and to formulate guidelines for safe and effective opioid stewardship.

Methods: The quantity of opioids prescribed (as Morphine Milligram Equivalents) at discharge and in the 90 days after surgery in adults with operatively treated, isolated fractures was correlated to patient demographics, comorbidities, fracture characteristics, and patient reported pain control.
Results: There were 56 males (47\%) and 63 females $(53 \%)$. Ankle fractures were the most common injury (34.2\%). 9 (7.6\%) fractures were open. The mean VAS pain scores at the first and second postoperative visits were 4.1 and 3.4, respectively. The mean initial quantity of opiates prescribed for all patients was $390 \mathrm{MME}$ and the mean total quantity was 535 MME (range 60-1800, Stdev 256; 60-2550, Stdev 245, respectively). 44\% of patients were prescribed refills. Greater 
quantity of MME prescribed at discharge correlated with higher pain scores at the first postoperative visit $(\mathrm{r}=0.25, \mathrm{p}=0.02)$ but not the second postoperative visit $(\mathrm{r}=0.17, \mathrm{p}=$ $0.15)$. There was no statistically significant association between MME prescribed and fracture characteristics or patient variables.

Conclusion: Postoperative opioid use correlated only with subjective, patient reported pain at the first postoperative visit, but did not correlate with injury mechanism, fracture characteristics, or patient variables.

https://doi.org/10.32873/unmc.dc.gmerj.2.1.063

\section{References}

1 Sairam Atluri, M.G.S., MD; Laxmaiah Manchikanti, MD, Assessment of the Trends of Medical Use and Misuse of Opioid Analgesics from 2004 to 2011. Pain Physician, 2014. 17: p. E119-E128.

2 Laxmaiah Manchikanti, M.A.S., BS, BA, Therapeutic Opioids: A Ten-Year Perspective on the Complexities and Complications the Escalating Use, Abuse, and Nonmedical Use of Opioids. Pain Physician, 2008. 11: p. S63-S88.
3 Boylan, M.R., et al., Patterns of Narcotic Prescribing by Orthopedic Surgeons for Medicare Patients. Am J Med Qual, 2018: p. 1062860618771190.

4 Attum, B., et al., Opioid Prescribing Practices by Orthopaedic Trauma Surgeons After Isolated Femur Fractures. J Orthop Trauma, 2018. 32(3): p. e106-e111.

5 Yu, N.N., et al., Persistence of Opioid Prescribing after a Forearm or Lower Leg Fracture. J Gen Intern Med, 2018. 33(3): p. 251-252.

6 Teng, Z., et al., Opioids contribute to fracture risk: a meta-analysis of 8 cohort studies. PLoS One, 2015. 10(6): p. e0128232.

7 Ping, F., et al., Opioids increase hip fracture risk: a meta-analysis. J Bone Miner Metab, 2017. 35(3): p. 289-297.

8 Buchheit, T., et al., Opioid exposure is associated with nonunion risk in a traumatically injured population: An inception cohort study. Injury, 2018.

9 Seth, P., et al., Quantifying the Epidemic of Prescription Opioid Overdose Deaths. Am J Public Health, 2018. 108(4): p. 500-502.

10 Bot, A.G., et al., Opioid use after fracture surgery correlates with pain intensity and satisfaction with pain relief. Clin Orthop Relat Res, 2014. 472(8): p. 2542-9.
11 Christensen, K.P., et al., The Effects of Anesthetic Technique on Postoperative Opioid Consumption in Ankle Fracture Surgery. Clin J Pain, 2016. 32(10): p. 870-4.

12 Finger, A., et al., Association Between Opioid Intake and Disability After Surgical Management of Ankle Fractures. J Am Acad Orthop Surg, 2017. 25(7): p. 519-526.

13 Helmerhorst, G.T.T., et al., Pain Relief After Operative Treatment of an Extremity Fracture: A Noninferiority Randomized Controlled Trial. J Bone Joint Surg Am, 2017. 99(22): p. 1908-1915.

14 McDonald, E., et al., Effect of Postoperative Ketorolac Administration on Bone Healing in Ankle Fracture Surgery. Foot Ankle Int, 2018: p. 1071100718782489.

15 Syed, U.A.M., et al., Neer Award 2018: the effect of preoperative education on opioid consumption in patients undergoing arthroscopic rotator cuff repair: a prospective, randomized clinical trial. $J$ Shoulder Elbow Surg, 2018. 27(6): p. 962-967.

\section{CD24 Expression in Follicular Lymphoma: An Alternative B-Cell Marker in Therapy Selected, Recurrent Lymphoma \\ Katrina Lancaster-Shorts ${ }^{1}$, Samuel Pirruccello'}

1 University of Nebraska Medical Center, Department of Pathology and Microbiology

Mentor: Samuel Pirruccello

Program: Pathology and Microbiology

Type: Original Research

Background: The rapidly expanding use of antigen targeted therapies, such as antiCD19, anti-CD20 and anti-CD22, in B-cell malignancies will require the application of additional B-cell-associated antigens in the assessment of residual disease. CD24 is a pan B-cell marker that undergoes significant surface density changes during normal maturation. In contrast to the loss of CD24 expression in normal follicles, we observed that follicle center derived lymphomas retain CD24 expression. Our aim was to determine the percentage of follicle center lymphomas with aberrant CD24 expression.

Methods: We reviewed 334 patients with a diagnosis of follicular lymphoma (FL; 228), large cell lymphoma of follicular origin (59) or B-cell lymphoma of follicular origin (47) by flow cytometry from October 2012 to August 2018. Cases without a confirmed tissue diagnosis of FL or diffuse large B-cell lymphoma (DLBCL) were excluded leaving 113 patients with FL, 38 patients with CD10positive DLBCL and 12 patients with mixed
FL/DLBCL. We analyzed the percentage of patients with CD24 positive lymphomas in each of the three diagnostic categories.

Results: We found that CD24 expression was retained in $89 \%$ of FLs $(101 / 113), 63 \%$ $(24 / 38)$ of DLBCLs and $42 \%(5 / 12)$ of mixed FL/DLBCL. Five cases of CD20 negative FL were $\mathrm{CD} 24$ positive.

Conclusion: Our results show the utility of aberrant CD24 expression in the identification of follicular lymphoma by flow cytometry.

https://doi.org/10.32873/unmc.dc.gmerj.2.1.065

\section{Performance of the Lymph2Cx Cell of Origin Classifier of Diffuse Large B-Cell Lymphoma in Comparison to Two Immunohistochemical Algorithms}

Katrina Lancaster-Shorts ${ }^{1}$, Ann Crowley ${ }^{1}$, Matthew Lunnin², Allison Cushman-Vokoun ${ }^{1}$, Jane Yuan¹, Catalina Amado ${ }^{1}$, Timothy Greiner ${ }^{1}$, Kai Fu¹, Hina Naushad Qureish ${ }^{1}$

${ }^{1}$ University of Nebraska Medical Center, Department of Pathology and Microbiology

${ }^{2}$ University of Nebraska Medical Center, Department of Internal Medicine, Division of Oncology and Hematology

Mentor: Naushad Qureishi

Program: Pathology and Microbiology

Type: Original Research

Background: Diffuse large B-cell lymphoma (DLBCL) is divided into cell-of-origin (COO) groups: germinal center B-cell (GCB), non-
GCB also known as activated B-cell (ABC) and intermediate/unclassified subgroups by mRNA gene expression profiling (mGEP). Immunohistochemical (IHC) classification algorithms, such as the Hans and Choi, were developed in lieu of mGEP on microarray, which could not analyze formalin fixed paraffin embedded (FFPE) tissue. The Nanostring Lymph2Cx assay is capable of
RNA gene expression profiling on FFPE tissue.

Methods: We studied 70 cases of DLBCL analyzed with the Lymph2Cx. Immunohistochemistry was performed on FFPE tissue sections using antibodies for CD10, BCL6, MUM1, GCET1 and FOXP1. Our aim was to determine the concordance 